\title{
A Thematic Analysis: How Can Online Learning Systems Boost Students Moods?
}

\author{
Rayna Kartika, Annisaa Rahman ${ }^{2}$ \\ ${ }^{1}$ Faculty of Economics, Universitas Andalas 1 \\ ${ }^{2}$ Faculty of Economics, Universitas Andalas 2 \\ *Corresponding author. Email: raynakartika@eb.unand.ac.id
}

\begin{abstract}
The pandemic Covid-19 has changed the way of learning from face to face meeting to online classes. As a consequence, the form of long-distance learning in this situation has given significant impacts on learning methods particularly to students and teachers. This research aims to investigate the factors which could trigger students' moods in online learning mode. Some students feel that online learning is ineffective, not only because of its difficulties but also because students easily get bored when they need to study online. This research use samples in Portfolio and Investment at Faculty of Economics of Universitas Andalas, Indonesia. Some methods are applied in the online learning process, the author then examined the result if it could boost the student's moods. Some indicators of online learning are set up to answer the proposed research questions. The result shows that utilizing technology accurately from both teacher and students during online synchronous and asynchronous learning is the best alternative to overcome boredom and difficulties during online learning.
\end{abstract}

Keywords: Online Learning, Synchronous, Asynchronous, Boredom, Long-distance Learning, Students' Satisfaction

\section{BACKGROUND}

Long distance learning has turned learning method from offline meeting into online meeting. This becomes a challenge for teachers and students who previously never did online learning. The research conducted by Rasheed et.al (2020) show that technology becomes an important factor in doing long distance learning. The key challenges for students are self-regulation and learning technology utilisation while the key challenge for teacher is involving of communication technology for teaching.

Portfolio Theory and Investment Analysis is an optional course subject in Accounting Department at Universitas Andalas. The subject conveys the theory and calculation of portfolio's risks and returns; thus, it makes the learning system becoming more complicated since teacher has two targets; making students understand the finance concept maintaining the students' attention for 2.5 study hours.
Previously, the teaching in this subject used mix method between teacher centred learning (TCL) and student- centred learning (SCL). The form of TCL is lecturing whereas teacher explain the material for 60 minutes. The SCL encouraged student's active participation through group presentation and case study. Sometimes, if needed, students havr to do simulation in the class to get a comprehensive understanding.

\subsection{Student Grading Systems}

The grading system has been divided into summative and formative assessments. Qu and Zhang (2013) have argued that summative and formative assessment have different form and different function. They should be combined together during the teaching and learning process. The combination of summative and formative also create a positive and pleasant ambience in the class. This 
learning method has become an alternative solution for student to boost their moods and interests.

Houston et.al (2017) argued that summative assessment practices were broadly criticised as distanced from the learning process. Recently discussion have refocused on the potential complementary characteristics of formative and summative purposes of assessment since assessment was repositioned as a communication process about learning. Through a variety of frequent assessment events, judgement of student performance is accompanied with rich feedback. To see it clearly, how the grading system will contribute to the learning process, the table has been shown below.

\section{Table 1. Students Grading System}

\begin{tabular}{|l|l|r|}
\hline No & Component & Weight \\
\hline \multicolumn{2}{|c|}{ 1. Summative Assessment } \\
\hline a. & Mid Term Exam & $25 \%$ \\
\hline b. & Final Exam & $30 \%$ \\
\hline c. & Group Assignments & $18 \%$ \\
\hline d. & Discussion Participation & $12 \%$ \\
\hline \multicolumn{2}{|}{ 2. Formative Assessment } \\
\hline a. & Interpersonal skills dimension & $5 \%$ \\
\hline b. & Interpersonal soft skills attribute & $5 \%$ \\
\hline c. & Attitude & $5 \%$ \\
\hline Total & $100 \%$ \\
\hline
\end{tabular}

\subsection{Grading Distribution}

The grading distribution for student in the previous year indicated that students had good understanding in the class of Theory Portfolio and Investment Analysis. $97 \%$ of students get good grade which is greater than B. The composition is $17 \%$ of students get score A, $29 \%$ of students get A-, and $43 \%$ and $8 \%$ of students get $\mathrm{B}+$ and $\mathrm{B}$, respectively. To see it detail, the chart below is shown.

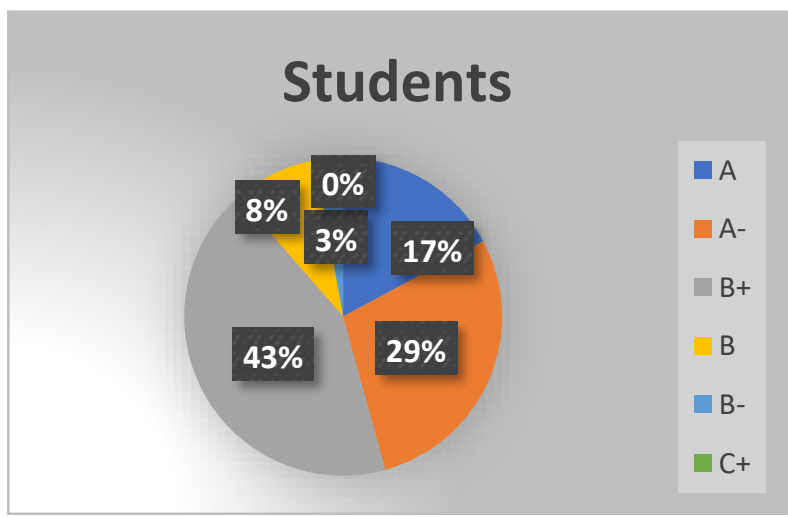

Figure 1. Grading Distribution

This year when the Covid-19 pandemic occurs, it is hoped that the online learning systems will not decrease the understanding of students to learn the course material. Teacher only needs to handle and find the solution how to boost student's moods so they will study collaboratively in assignment and independently for exams and quiz. According to Williams and Williams (2011), there are five key ingredients impacting student motivation, namely; students, teachers, content, method/process, and environment. If these five key ingredients ae fulfilled and carried out properly with theirresponsibilities, the harmony of learning process can be achieved in the online class.

\subsection{Research Objectives}

The research objectives are to assist students to understand the material and boost the students' moods to do online learning. To make it more detailed, the research objectives are as follows;

1. To enhance the students' understanding on learning material and boost their moods to do online learning.

2. To examine the optimal extent of which can be carried out to teaching materials in an online learning.

3. To find out each responsibilities or functions to achieve harmonious and successful online learning among teacher, students, contents, process/method, and learning environment.

\section{OUTCOME TARGETED STRATEGY}

During Covid-19, the learning method between teacher and students have been modified into long distance learning. This method has two forms, synchronous and asynchronous. The first one consists of live synchronous and virtual synchronous while the latter consists of self-paced asynchronous and collaborative asynchronous. Live synchronous is a learning process where both teacher and students are in the same place and time, the examples of this are lecturing, discussion, and etc. Virtual synchronous is a learning method where teacher and students are at the same time but different place. The example of this is virtual conference. Selfpaced asynchronous is an online learning process that is done by student himself. The example is doing online simulation. The last one is collaborative asynchronous, where teachers and students work collaboratively., such as in a discussion forum. Zydney (2020) adds that blended synchronous environments offer benefits to learners in terms of flexibility, but there are technological and pedagogical challenges in implementing this approach.

This course subject will use three of them, those are virtual synchronous, self-paced asynchronous, and collaborative asynchronous. For each of them, between teacher and students will utilize this learning method through ILearning. ILearning is an LMS which ease the online learning process between teacher and students. One of the strategies on ILearn platform is to include animated video to describe and explain the material. Some animated video can be made through in Power point and PowToon. Microsoft power point is quite familiar for both teacher and students but somehow, they have not utilised the features which can give benefit to explain the material. The latter is an application which provides some useful features. PowToon is more friendly with more features in it. 
By having different method of learning that has been implemented in online learning, more literature studies are conducted to see which variables are suitable implemented in the class.

\section{METHODS}

This research is using a qualitative design where the author will find the answers proposed in this research through literature review. This research is to seek the factors of successful online learning methods delivery by content analysis related to enhance students in learning material and boost their moods to learn online.

In this research the author will gather as much information to obtain the strategy to do effective online learning. After that, the author will group the mechanisms of action needs to be done in the distance learning. The action that will later be developed based on needs to be adjusted in the semester learning plan. The semester learning plan will show some information on how the class will be conducted whether in synchronous or asynchronous way.

Based on the research objectives that have been set up previously, the target of effective online learning and the methods to boost student's moods have been outlined the indicators as follows:

1. the effectivity and efficiency of online learning delivery

2. the benefits and drawbacks of online learning in the pandemic Covid-19

3. the optimalisation of features and delivery material in online learning

4. the acceptance of students using online learning as media to deliver material

5. the difficulties and challenge of utilising online media in learning process

Students are very delighted to have online learning since it can assist their learning process effectively and efficiently. From the given indicators, the authors will analyse the related literature which discusses these elements in order to adjust the outcome-based education (OBE) semester learning plan for distance-learning. These indicators will also be implemented in order to answer the proposed research questions.

\section{RESULT AND DISCUSSION}

The findings of this research show that the effectivity and efficiency of online learning delivery can be achieved by several factors. According to Gettoufi (2011), blackboard is the most developed and most expensive LMS which is built with five systems, they are learning, community, portfolio, content and outcomes. Another author implied that online pedagogical tools enables students to write, share, answer, discuss, and rate multiple choice questions with little to no input from the instructor-had better learning outcomes and improved perceptions (Nguyen, 2015). Having said that online learning is effective and efficient for both teacher and students, the technology plays significant and crucial factors. Network, infrastructure, media, and humans are the factors which can assist the process of online learning become more effective and efficient. Lagging and buffering in internet working, unsupported media to access online learning, and human illiteracy in utilising media are the most reasons why online learning is not effective and efficient.

The benefits and drawbacks of online learning method have been discussed by several journals. One of the authors discusses about the benefit of conducting online learning as its use as professional development, its cost effectiveness, credit equivalency, the possibility providing a world class education to anyone with good network. While the drawbacks are online learning needs more focus from students, particularly to understand the materials. Another drawback proposed by the author is that online learning must be supported by adequate media which means that the tools are not cheap, so, for some students who cannot afford the media or the gadgets, this online learning will be a serious issue. Therefore, the environment to conduct online learning is very necessary to consider since there are several factors influencing the online learning mode.

Nguyen (2015) also has described previously about online learning, he has mentioned that positive learning outcomes will be improving learning as measured by test scores, student's engagement with the class materials, the possibility of providing a world class education to anyone with a broadband connection.

The optimalisation of features in technology and delivery material in online learning occurs between teacher and students. Online design education should be integrated with various educational values and functional features in a systematic manner and requires designing learning evaluation protocol as part of learning activities and communicative forms within online-based learning sites (Park, 2011). This features of technology can include the animated video, interactive discussions between peer to peer, or peer to teacher, and quiz.

The acceptance of students using online learning as media to deliver material have been conducted by several researchers. Park (2011) mentions that there are three components for online learning via virtual learning environment (VLE) including an interactive delivery structure, communication channels, and learning evaluation. Zamari et.al (2012) conduct a research which focuses on students perceptions on the issue of online learning. The main issues are the frequency of website visit, choice, recommendation, the problem students faced, their opinion on the effectiveness of this task, and student initiative to access the website. In addition, Wei et.al (2017) also cites that the relationships among student's self-reported use of interactive functions, and student's actual use logs have some direct influences on students online learning performance, such as online discussion scores, exam sores, and group project scores. 
The difficulties and challenges of utilising online media in learning proces, according to Song et.al (2004) are technical problems, a perceived lack of sense of community, time constraint, and the difficulty in understanding the objectves of the online courses.

There is a difference between student's motivation and achievement, using blended learning model and students using direct learning model. Student's motivation and achievement are much greater of students using blended learning rather than direct learning model (Islam et.al, 2018). It indicates that blended learning model has boosted student's moods. Another solution has been oferred by Pastushenko et.al (2018). One of the ways to boost student's moods is using virtual learning environments based on innovative educational mechanics, such as gamification. (Pastushenko et.al, 2018). Song et.al (2004) also argues that most leaners agreed that course design, learner motivation, time management, and comfortableness with online technologies are the impacts of success on online learning experience.

Based on the information gathered from the literature review, the semester learning plan will be revised accordingly to online distance learning with the use of technology development in materials delivery. It is hoped that the semester learning plan will be implemented in the online learning mode after considering several factors that have been mentioned and explored previously.

\section{CONCLUSION}

The conclusion that can be withdrawn from this research re as follows;

1. The correct tools and media used in Online learning can assist the process of learning system for both teachers and students with the correct protocols.

2. Online learning can boost student's mood by considering several factors those are students, teacher, content, process, and environment.

3. One of the ways to boost student's moods is by creating the learning mechanism into gamification such as animated video, interactive communication, and quiz.

4. The technology used in online learning must be optimised in order to create a harmonious environment in distance learning mode.

5. The responsibility of each element in distance learning must be followed by certain protocol which allow students and teacher conduct their role properly.

\section{AUTHORS' CONTRIBUTIONS}

The author has contributed equally to this research. The first author has managed the semester learning plan from the indicators which have been set up in this research, while the second author also creates the focus to learning development especially in the technology tools. Both authors create animated video to make students understand more to the course subject and to boost student's moods in online learning.

\section{ACKNOWLEDGMENTS}

The author would like to say gratitude to Lembaga Pengembangan Pendidikan dan Penjaminan Mutu (LP3M) Universitas Andalas for the learning development grant.

\section{REFERENCES}

[1] Gettoufi, Bechir, The Effectiveness and Efficiency of E-Learning Tools, October 2011 DOI: https://doi.org/10.13140/2.14319.8246

[2] Houston, Don and Thompson, James N., Blending Formative and Summative Assessment in a Capstone Subject: It's Not Your Tools, It's How You Use Them. Joural of University Teaching and Learning Practice, 14 (3). 2017.

[3] Islam, Syaiful., Baharun, Hasan., Muali, Chusnul., Ghufron, Mohd Idil., Mushfi, Ei Iq., Wijaya, Muslim., and Marzuki, Ismail., To Boost Student's Motivation and Achievement through Blended Learning. Journal of Physics: Conference Series, Volume 114. 2018.

[4] Nguyen, Tuan, The Effectiveness of Online learning: Beyond No Significant Difference and Future Horizons. Journal of Online Learning and Teaching, Vol. 11 No. 2. June 2015.

[5] Park, Ji Yong, Design Education Online: learning delivery and Evaluation. The International Journal of Art \& Design Education, 2011, pp. 53-113. DOI: https://doi.org/10.1111/j.1476.8070.2011.0168 9.X

[6] Pastushenko, Olena., Hruska, Tomas., and Zendulka, Jeroslav., Increasing Student's Motivation by Using Virtual Learning Environments based on Gamification mechanics: Implementation and 
Evaluation of Gamified assignments for Students., TEEM18. Proceedings of the Sixth International Conference on Technology Ecosystems for Enhancing Multiculturality, October 2018. DOI: https://doi.org/10.1145/3284179.3284310

[7] Qu, Wenji., and Zhang, Chunling., Journal of language Teaching and Research. Vol 4 No 2. Pp 335-339. March 2013. Academy Publisher Manufactured in Finland. DOI: https://doi.org/10.4304/jtr.4.2.335.339

[8] Rasheed, Abu Bakar Rasheed, Kansin, Amirudin, and Abdullah, Nor Aniza. Teacher Challenges, The Use of Technology for Teaching. Computers \& Education, volume 144, January 2020

[9] Song, Liyan., Singleton, Ernise S., Hill, Jannete R., Koh, Myung Hwa., Improving Online Learning: Student's perceptions of Useful and Challenging Characteristics. The Internet and Higher Education vol. 7. Issue 1, $1^{\text {st }}$ Quarter 2004. Elsevier.

[10] Wei, Huei- Chuan., Peng, Hsinyi., and Chou, Chien. Can More Interactively Inprove Learning Achievement in an Online Course Management Systems on their Learning Achievement. Journal Computers and Education. 2015 Vol 83. DOI: https://doi.org/10.1109/2.161279

[11] Williams, Kaylene C \& Williams, Caroline C. Five Keys Ingredients for Improving Motivation Research in Higher Education Journal. Vol. 11. https://aabri.com/manuscripts/11834.pdf

[12] Zamari,., Zarlina Mohammad., Adnal, Airi Haimi Mohammad., Yusof, Sheem Liza Idris Johana., Student's Perception of Using Online Language Learning Materials. ProcediaSocial and Behavioral Sciences, 2012. Vol. 67.

DOI: http://doi.org/10.1016/j.sbspro.2012.11.367

[13] Zydney, Janet Mannheimer., Warner, Zachary. And Angelone, Laurem, Learning through Experience, Using Design-based Research to Redesign Protocols for Blended Synchronous Learning Environment. Computers and Education, Vol. 143, January 2020. 